\title{
Clinical value of pulmonary metastasectomy for thyroid malignancies: a systematic review and meta-analysis
}

\author{
Yusuf Dundar MD, Quinton Mandle, Julie Samantray MD, Jeffrey Hotaling MD, Syed M. Rizvi, \\ John Cramer MD, Ho-Sheng Lin MD, Syed Naweed Raza
}

\begin{abstract}
Background: There is currently no consensus on the role of pulmonary metastasectomy (PM) for thyroid malignancies. The main objective of this study is to determine if there is any survival benefit to PM and determine good candidates for metastasectomy.

Methods: A systematic review of relevant studies was performed, evaluating articles identified using the PubMed, Cochrane, and MEDLINE databases according to PRISMA-guidelines.

Results: The initial literature search yielded 18 articles of which 7 met inclusion criteria. Only data on thyroid cancers were included in the systematic review. A total of 174 patients who underwent PM were analyzed. The mean age was 54.8 (range: $10-90$ ), and $52.5 \%$ of patients were female. The overall absolute 5-year survival rate was $67.7 \%$ (range: 32.5 $84.0 \%)$ for patients undergoing PM. The reported post-surgical complication rate overall was $14.4 \%$ and two peri-operative deaths were reported. Three papers reported the following as good prognostic factors: Papillary histology, younger age ( $<45$ years), disease free interval $>3$ years, RO (microscopic margin free) resection, systematic lymphadenectomy, thyroglobulin $<10 \mathrm{ng} / \mathrm{mL}$, and thyroglobulin reduction $>80 \%$ after metastasectomy.

Conclusion: This study is the first systematic review evaluating the clinical role of PM for thyroid cancer in the literature to date. PM may offer prolonged survival over traditional therapy for selected patients.
\end{abstract}

Keywords: Thyroid malignancy, pulmonary metastasis, metastasectomy, survival outcomes

\section{INTRODUCTION}

Thyroid cancer is the most common endocrine malignancy worldwide, and the reported prevalence of thyroid cancer is increasing., ${ }^{1,2}$ While select early stage thyroid cancers may be observed or treated with thyroid lobectomy alone, the standard treatment of thyroid cancer consists of surgical resection with total thyroidectomy sometimes followed by radioactive iodine (RAI), which ablates residual primary tumor and metastases., ${ }^{3,4}$ This approach is generally

Corresponding author: Yusuf Dundar Contact Information: Ysfdndr@gmail.com DOI: 10.12746/swrccc.v7i31.583 effective, resulting in a no evidence of disease status in most patients and achieving an overall estimated 85\%-93\% 10-year survival rate in patients with differentiated thyroid malignancies. ${ }^{4,5}$ Thyroid cancer tends to invade locoregional lymph nodes and uncommonly invades distant nodes, with estimated rates ranging from $4 \%$ to $30 \%$. $^{2,4,6,7}$ However, distant metastasis is strongly associated with poor treatment outcomes and reduced long term survival. The majority of distant metastases occur in the chest, with the most common site being the lung. ${ }^{3,4,5}$ Radioactive iodine is the first line treatment protocol in patients with pulmonary metastasis; unfortunately, RAl is not always curative, and more than half of patients experience disease progression despite repeated ablations, resulting in a reported 10 -year survival rate of $10-18 \%$ for RAI 
treatment in patients with pulmonary metastasis. ${ }^{8,9,10}$ Molecular targeted therapy for locally advanced or metastatic iodine-refractory differentiated thyroid cancer (DTC) have been approved; however, while these approaches prolong survival, outcomes are unsatisfactory. ${ }^{11,12,13}$

Surgical resection of head and neck and upper mediastinal metastases can prove effective for patients with RAl-resistant disease, but resection of pulmonary metastases is more controversial, despite its having a standard role in the treatment of other malignancies, including sarcomas, germ cell tumors, and other carcinomas. ${ }^{4,7}$ Several studies suggest that pulmonary metastasectomy (PA) may be an effective treatment option in RAI refractory pulmonary metastasis. However, there is currently no consensus among practitioners regarding its use, indications, and associated morbidity and mortality in thyroid cancer patients. We therefore aim to systematically analyze the literature examining the role of PM in thyroid cancer to better delineate its clinical value.

\section{Methods}

\section{SEARCH STRATEGY}

Articles reporting pulmonary metastasectomy in patients with thyroid malignancies were systematically identified using the electronic PubMed, Cochrane, and MEDLINE databases. Keywords used included "pulmonary metastasectomy" (PM), "lung metastasectomy" AND" thyroid cancer" or "thyroid malignancy" or "papillary thyroid cancer" or "follicular thyroid cancer." Only articles published in English were considered for review. One hundred and seventy-four abstracts were reviewed, and 155 of these articles were excluded from further consideration (Figure 1). All remaining articles $(n=18)$ were analyzed using selection criteria based on PRISMA guidelines.

\section{SELECTION CRITERIA}

Our inclusion criteria required that the study: 1) describe patients who underwent pulmonary metastasectomy for thyroid cancers, and 2) provide treatment outcomes of pulmonary metastasectomy. We excluded papers if they: 1) only detailed pulmonary metastasectomy for patients who didn't have thyroid malignancy, 2) provided information for fewer than five patients, and 3) did not describe treatment outcomes. All articles remaining after applying exclusion criteria $(n=7)$ were included in the systematic review and meta-analysis.

\section{DATA EXTRACTION}

From seven retrospective chart reviews, we extracted the following information to include in our database: total number of thyroid cancer patients who underwent PM, mean age at thyroid cancer diagnosis, age range for all patients, type of surgical approach used for PM, number and type of surgical complication, five-year survival rate, sex, average age, laterality of pulmonary metastases, perceived favorable prognostic factors, and primary tumor pathology. Data were then tabulated in Excel and statistical analysis was performed for cumulated data. Demographic variables, treatment outcomes, and complication rates were calculated by using descriptive statistics. Heterogeneity was examined by using Cochrane's $Q$ test and $\mathrm{I}^{2}$ statistic.

\section{RESULTS}

Seven studies published between 1998 and 2017 were reviewed. The total number of patients with a thyroid cancer diagnosis who underwent PM was 174 . Of the patients whose sex was provided $(n=107)$, $52.3 \%$ were male, $47.7 \%$ were female, and the average patient age was 54.8 with a pooled age range of 10-90. Characteristics of the seven studies, including patient age and sex, are reported in Table 1. The most common primary thyroid tumor pathology was papillary $(48.0 \% ; n=73)$, followed by follicular $(37.5 \%$; $n=57)$, medullary $(7.9 \% ; n=12)$, Hurthle $(5.9 \% ; n=$ $9)$, and anaplastic $(0.7 \%, n=1)$. The distribution of thyroid cancer histology is summarized in Figure 2. Pulmonary metastases were more frequently reported to be bilateral $(n=57)$ than unilateral $(n=37)$, and thoracotomy $(n=68)$ was more frequently used as the surgical approach to PM than sternotomy $(n=28)$ or thoracoscopy $(n=14)$. 
Figure 1. Flow chart describing identification of studies to be included in the systematic review. Adopted from PRISMA guidelines.
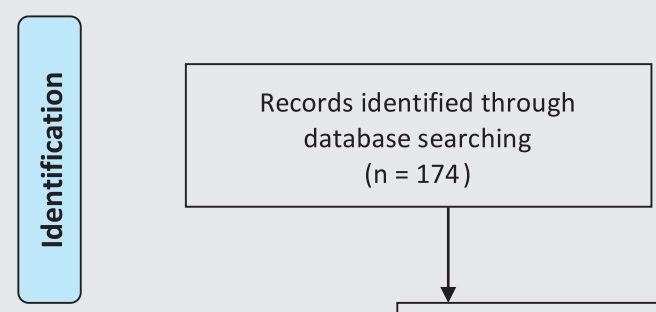

Additional records identified through other sources $(n=174)$

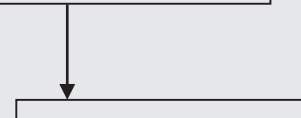

Records after duplicates removed $(n=174)$
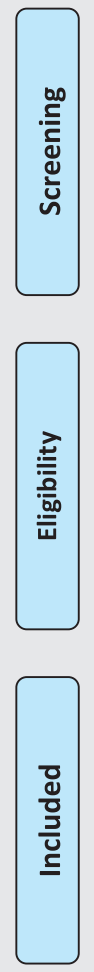
qualitative synthesis $(n=7)$

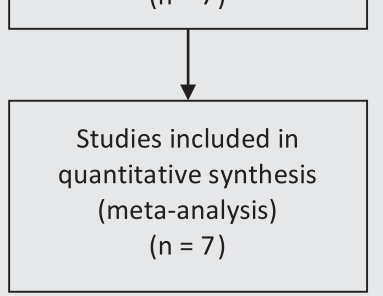

From: Moher D, Liberati A, Tetzlaff J, Altman DG, The PRISMA Group (2009). Preferred Reporting /tems for Systematic Reviews and MetaAnalyses: The PRISMA Statement. PLoS Med 6(7):e1000097. doi:10.1371/journal.pmed1000097

For more information, visit www.prisma-statement.org.
The overall absolute 5-year survival rate post-PM was $67.7 \%$ (average survival rate based on pooled data) with a pooled range of $32.5 \%-84.0 \%$; one paper did not report the 5-year survival rate. Sampson et al reported a 3-year survival rate of $77 \%$, and Porterfield et al and Moneke et al reported $37.5 \%$ and $56 \%$ survival rates, respectively, at 10 years post-surgery (Table 2). Three papers described favorable prognostic factors for patients who underwent PM, with two papers reporting young age ( 45 years old) at initial cancer diagnosis and papillary histology of the primary tumor (Figure 3a, Figure $3 b$ ) as predictors of a favorable outcome. Others included a disease free interval of greater than three years, iodine avidity of the thyroid cancer, thyroglobulin levels of less than $10 \mathrm{ng} / \mathrm{mL}$ (Figure 3c), thyroglobulin level reduction of $80 \%$ post-metastasectomy, age less than 45 at time of thyroid cancer diagnosis, R0 (negative microscopic margins) metastasectomy, and systematic mediastinal lymphadenectomy. 
Table 1. Study and Patient Characteristics

\begin{tabular}{|c|c|c|c|c|c|c|c|}
\hline Author & Year & $\begin{array}{l}\text { Study } \\
\text { country }\end{array}$ & $\begin{array}{l}\text { No. } \\
\text { patients }\end{array}$ & $\begin{array}{l}\text { Males } \\
(\%)\end{array}$ & $\begin{array}{l}\text { Females } \\
(\%)\end{array}$ & Mean age & $\begin{array}{l}\text { Age } \\
\text { range }\end{array}$ \\
\hline $\operatorname{Khan}^{21}$ & 1998 & USA & 8 & ND & ND & ND & ND \\
\hline Liu $^{11}$ & 1999 & USA & 8 & ND & ND & ND & ND \\
\hline Protopapas $^{22}$ & 2001 & England & 16 & $12(75.0)$ & $4(25.0)$ & 47 & $19-77$ \\
\hline $\mathrm{Pak}^{4}$ & 2003 & USA & 29 & $12(41.3)$ & $17(58.6)$ & 48 & $12-72$ \\
\hline Sampson $^{23}$ & 2007 & Canada & 22 & $7(31.8)$ & $15(68.1)$ & 68 & $19-70$ \\
\hline Porterfield $^{2}$ & 2009 & USA & 48 & $25(52.0)$ & $23(47.9)$ & 53 & $20-79$ \\
\hline Moneke $^{7}$ & 2017 & Germany & 43 & $19(44.1)$ & $24(55.8)$ & 57 & $10-77$ \\
\hline TOTAL & & & 174 & $75(47.4)$ & $83(52.5)$ & & \\
\hline
\end{tabular}

"ND" signifies that the data was not provided by the study.

The most common complications from PM reported in the seven papers were transient atrial fibrillation (total number of patients $=3$ ) and surgical wound infection (total number of patients $=3$ ). However, only 25 out of 174 patients (14.4\%) were reported to have complications post-surgery, and only two patients died due to surgical complications. All observed complications are described in Table 3.

\section{Discussion}

The first-line treatment for thyroid cancer metastasis to the lung is radioactive iodine (RAI), which offers only a $50 \%$ survival rate at six months and less than a $20 \% 10$-year survival rate. 5,14 Having RAl refractory PM is considered a poor prognostic factor. In contrast, pulmonary metastases secondary to renal

\section{Frequency of Thyroid Tumor Histotype}

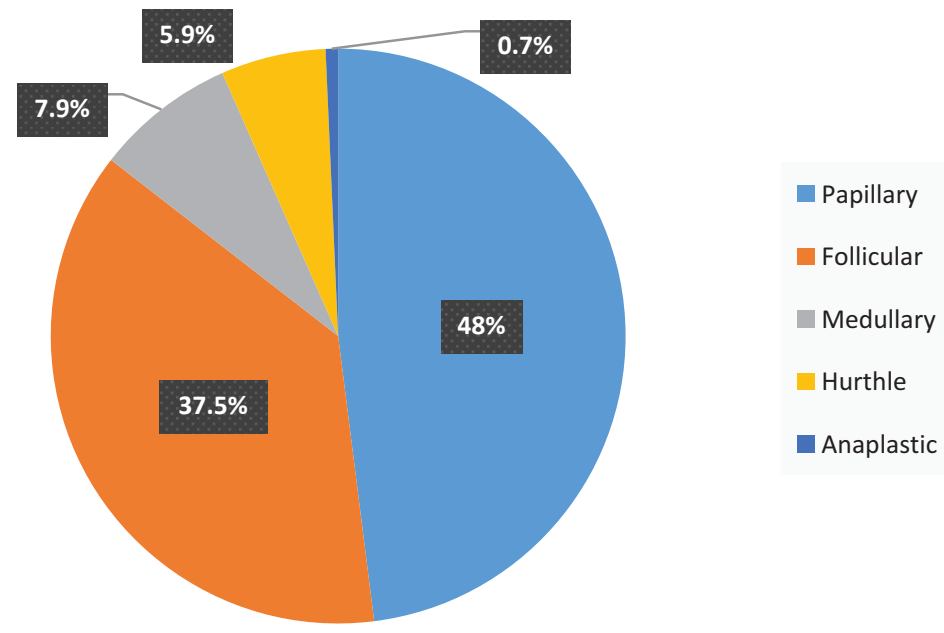

Figure 2. Distribution of pooled primary thyroid tumor histologies for all studies. 
Table 2. Survival Outcomes

\begin{tabular}{|l|c|c|c|}
\hline Author & 3-Year & 5-Year & 10-Year \\
\hline Khan $^{21}$ & & 58.0 & \\
\hline Liu $^{11}$ & & 75.0 & \\
\hline Protopapas $^{22}$ & & 32.5 & \\
\hline Pak $^{4}$ & & 78.5 & \\
\hline Sampson $^{23}$ & 77.0 & & \\
\hline Porterfield $^{2}$ & & 60.0 & 37.5 \\
\hline Moneke & & 84.0 & 56.0 \\
\hline
\end{tabular}

cell carcinoma, colorectal carcinoma, testicular cancers, and sarcomas are routinely treated surgically. ${ }^{14}$ Similarly, Finley et al found that those undergoing PM for squamous cell carcinomas of the head and neck (selected patients with limited pulmonary metastasis) had significantly higher survival rates than those who did not. ${ }^{15}$ Considering the success of PM in improving survival in patients with other cancers, it is likely that surgical resection of metastases could improve outcomes for thyroid cancer patients with pulmonary metastases. The data collected from these

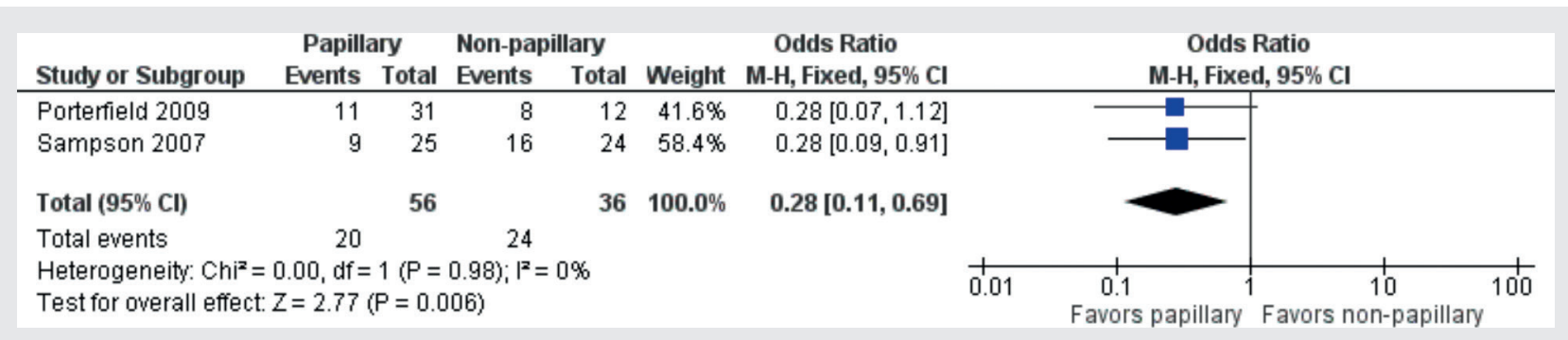

Figure 3a. Overall 5-year survival rates for histologic subtypes.

\begin{tabular}{|c|c|c|c|c|c|c|c|c|c|c|}
\hline \multirow{2}{*}{ Study or Subgroup } & \multicolumn{2}{|c|}{ Papillary } & \multicolumn{2}{|c|}{ Non-papillary } & Weight & $\begin{array}{c}\text { Odds Ratio } \\
\text { M-H, Fixed, } 95 \% \mathrm{CI}\end{array}$ & \multicolumn{4}{|c|}{$\begin{array}{c}\text { Odds Ratio } \\
\text { M-H, Fixed, 95\% Cl }\end{array}$} \\
\hline & 23 & 31 & 11 & 12 & $28.1 \%$ & $0.26[0.03,2.36]$ & & $\rightarrow$ & & \\
\hline Sampson 2007 & 9 & 25 & 16 & 24 & $71.9 \%$ & $0.28[0.09,0.91]$ & & & & \\
\hline Total (95\% Cl) & & 56 & & 36 & $100.0 \%$ & $0.28[0.10,0.78]$ & & & & \\
\hline Total events & 32 & & 27 & & & & & & & \\
\hline $\begin{array}{l}\text { Heterogeneity: } \mathrm{Chi}^{2}= \\
\text { Test for overall effect }\end{array}$ & $\begin{array}{l}0.00, d f= \\
Z=2.42\end{array}$ & $\begin{array}{l}1(P= \\
P=0.0\end{array}$ & $\begin{array}{l}0.95) ; 1^{2}= \\
\text { 2) }\end{array}$ & & & & 0.01 & $\begin{array}{c}0.1 \\
\text { Favors papillary }\end{array}$ & $\frac{10}{\text { Favors non-papillary }}$ & 100 \\
\hline
\end{tabular}

Figure 3b. Overall 10-year survival rates for histologic subtypes.

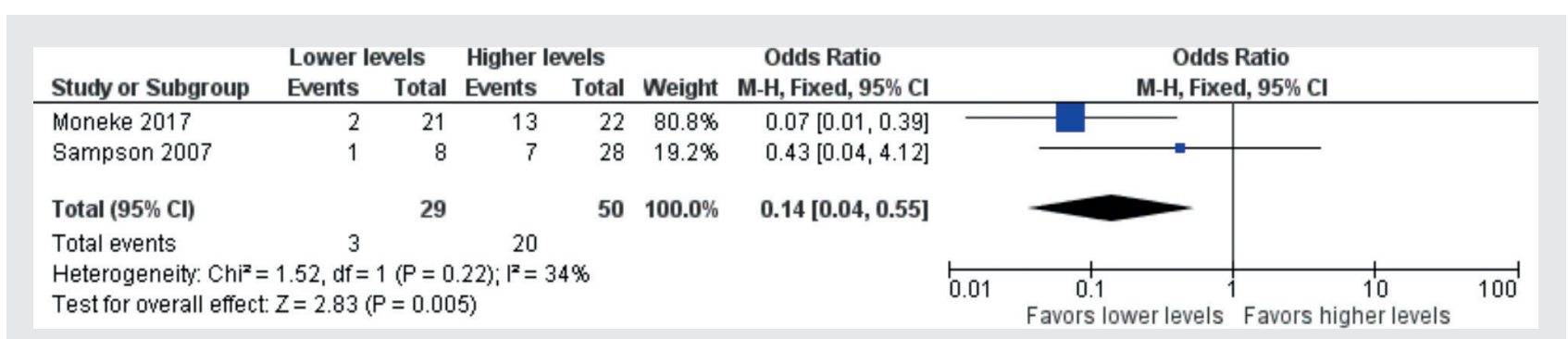

Figure 3c. Overall survival rates for post-operative thyroglobulin levels. 
Table 3. Adverse outcomes following pulmonary metastasectomy

\begin{tabular}{|l|c|}
\hline Outcome & Number \\
\hline Atrial Fibrillation & 3 \\
\hline Surgical Wound Infection & 3 \\
\hline Respiratory Distress & 2 \\
\hline Hemorrhage & 2 \\
\hline Chylothorax & 2 \\
\hline Death & 2 \\
\hline All others & 11 \\
\hline TOTAL & 25 \\
\hline
\end{tabular}

"All others" includes hypotension, brachial plexus injury, nerve paresis, Horner syndrome, pneumonia, ileus, and sternal dehiscence.

retrospective chart reviews do, in fact, suggest that pulmonary metastasectomy in thyroid cancer patients can greatly decrease mortality with an absolute overall 5-year survival rate of $67.7 \%$ reported. Given that this rate greatly exceeds those of RAI reported in the literature, this would suggest that PM is potentially a highly effective treatment for RAl-refractory metastases. More important, PM appears to carry a low risk of morbidity and mortality. Only $14.4 \%$ of all patients experienced a surgical complication, and only two out of 174 patients died as a result of surgery. Considering the significant decreases in mortality reported by all seven papers, it therefore seems likely that the benefits to PM outweigh the risks.

The advent of effective multitargeted kinase inhibitors for recurrent/metastatic DTC creates another option for patients with PM from iodine refractory thyroid cancer. In particular, the multitargeted kinase inhibitor lenvatinib was approved for iodine-refractory recurrent/metastatic disease on the basis of progression free survival improvements in the phase III SELECT trial greater than had been achieved in other placebo-controlled trials in DTC..$^{11,12,13}$ The $65 \%$ response rate and improvement in progression free survival from 3.6 months to 18.3 months creates an attractive potential alternative option. None of the studies that we identified compared results with PM versus targeted therapy. Future studies could compare outcomes of either multitargeted kinase inhibitors or combination therapy. Since many patients with metastatic DTC will have prolonged survival, they may benefit from such an aggressive approach.

In 1947 Alexander and Haight suggested the first known selection criteria for PM, which were later revised by Thompson in 1965 . These are: 1) the primary tumor must be controlled, 2) no extrathoracic metastases exist, with the exception of hepatic metastases, 3) the metastases are resectable, and 4) the risks of surgery are acceptable. ${ }^{16,17}$ Additionally, the International Registry of Lung Metastases lists disease free index, complete resection, and number of nodules as favorable prognostic factors. ${ }^{18}$ Although these criteria are used today by surgeons to guide selection of patients for PM, there is no current consensus on favorable prognostic factors for patients with thyroid cancer metastases to the lung specifically. The reviewed literature suggests that younger patients have a lower mortality rate. However, whether older age should be considered a relative contraindication for PM or simply increases disease-specific mortality regardless of treatment modality is unclear. ${ }^{19}$ Additionally, although it appears that papillary thyroid carcinoma carries a better prognosis over other thyroid cancer histotypes post-metastasectomy, it is possible that this trend is due to the lower mortality of papillary thyroid carcinoma in general. ${ }^{20}$ Thyroglobulin levels of lower than $10 \mathrm{ng} / \mathrm{mL}$ and relative decreases of at least $80 \%$ have been suggested by Moneke et al to positively correlate with improved survival. ${ }^{7}$ Furthermore, they reported that R0 (microscopic negative margins) resection of pulmonary metastases is associated with a significantly increased survival rate versus incomplete resection, and that systematic mediastinal lymphadenectomy also significantly decreases mortality, possibly through improved cancer staging in addition to removal of the metastases. ${ }^{7}$ These findings suggest that outcomes can be improved with more complete surgical resection, supporting the role of aggressive treatment in these patients.

Admittedly, this study has several limitations, mainly owing to the small number of papers that met our inclusion criteria. There are few studies that specifically examine the role of pulmonary metastasectomy 
in thyroid cancer treatment, and to our knowledge there are no prospective studies that compare morbidity and mortality rates between medical and surgical treatment in these patients. It is therefore difficult to determine precisely the degree to which PM improves survival rate over RAl and other treatment modalities. Additionally, even among the seven papers that met our inclusion criteria there is heterogeneity in the outcomes and patient characteristics measured. Therefore, we can only draw limited conclusions regarding survival rates, surgical complications, and prognostic factors. Future randomized studies should compare PM to other treatment modalities, including $\mathrm{RAl}$ alone, to conclusively determine that it provides a statistically and clinically significant benefit and to more completely determine whether it is safe both peri-operatively and long-term. Additional research should seek to define prognostic factors for morbidity and mortality and to identify characteristics of good surgical candidates.

\section{Conclusion}

This is the first study to systematically review the role of pulmonary metastasectomy in patients with thyroid cancer; the study design was adapted from PRISMA checklist (Table 4). The data collected in our study demonstrate that PM is associated with superior survival rates to those reported for radioactive iodine treatment alone, with approximately two-thirds of patients surviving at five years' follow-up. Moreover, PM appears to be associated with low morbidity and a very low mortality rate suggesting that it is both a safe and effective option for patients when indicated. Factors that seem to indicate a favorable prognosis after metastasectomy include papillary histology of the primary tumor and young age of the patient at the time of thyroid cancer diagnosis; lower thyroglobulin levels and more aggressive surgical treatment possibly improve outcomes. It is possible that these characteristics may be used to select good surgical candidates. In patients with pulmonary metastases secondary to thyroid cancer, surgical intervention should be considered after radioactive iodine ablation fails in patients without contraindications. We recommend prospective randomized studies be conducted to confirm that a survival benefit for PM over RAI alone exists. Future studies should also try to better characterize indications for surgery and to assess long-term morbidity of PM.

Table 4. PRISMA checklist

\begin{tabular}{|l|l|l|l|}
\hline Section/topic & \# & Checklist item & $\begin{array}{l}\text { Reported } \\
\text { on page \# }\end{array}$ \\
\hline TITLE & 1 & Identify the report as a systematic review, meta-analysis, or both. & 1 \\
\hline Title & & $\begin{array}{l}\text { Provide a structured summary including, as applicable: background; } \\
\text { objectives; data sources; study eligibility criteria, participants, and } \\
\text { interventions; study appraisal and synthesis methods; results; limitations; } \\
\text { conclusions and implications of key findings; systematic review registration } \\
\text { number. }\end{array}$ & 1 \\
\hline $\begin{array}{l}\text { Structured } \\
\text { summary }\end{array}$ & 3 & $\begin{array}{l}\text { Describe the rationale for the review in the context of what is already known. } \\
\text { INTRODUCTION }\end{array}$ & 2 \\
\hline Rationale & $\mathbf{l}$ & $\begin{array}{l}\text { Provide an explicit statement of questions being addressed with reference } \\
\text { to participants, interventions, comparisons, outcomes, and study design } \\
\text { (PICOS). }\end{array}$ & 2 \\
\hline Objectives & & \\
\hline
\end{tabular}


Table 4. PRISMA checklist (Continued)

\begin{tabular}{|c|c|c|c|}
\hline Section/topic & \# & Checklist item & $\begin{array}{l}\text { Reported } \\
\text { on page \# }\end{array}$ \\
\hline \multicolumn{4}{|l|}{ METHODS } \\
\hline $\begin{array}{l}\text { Protocol and } \\
\text { registration }\end{array}$ & 5 & $\begin{array}{l}\text { Indicate if a review protocol exists, if and where it can be accessed (e.g., } \\
\text { Web address), and, if available, provide registration information including } \\
\text { registration number. }\end{array}$ & $\mathrm{n} / \mathrm{a}$ \\
\hline Eligibility criteria & 6 & $\begin{array}{l}\text { Specify study characteristics (e.g., PICOS, length of follow-up) and report } \\
\text { characteristics (e.g., years considered, language, publication status) used as } \\
\text { criteria for eligibility, giving rationale. }\end{array}$ & 2,3 \\
\hline $\begin{array}{l}\text { Information } \\
\text { sources }\end{array}$ & 7 & $\begin{array}{l}\text { Describe all information sources (e.g., databases with dates of coverage, } \\
\text { contact with study authors to identify additional studies) in the search and } \\
\text { date last searched. }\end{array}$ & 2,3 \\
\hline Search & 8 & $\begin{array}{l}\text { Present full electronic search strategy for at least one database, including any } \\
\text { limits used, such that it could be repeated. }\end{array}$ & 2,3 \\
\hline Study selection & 9 & $\begin{array}{l}\text { State the process for selecting studies (i.e., screening, eligibility, included in } \\
\text { systematic review, and, if applicable, included in the meta-analysis). }\end{array}$ & 2,3 \\
\hline $\begin{array}{l}\text { Data collection } \\
\text { process }\end{array}$ & 10 & $\begin{array}{l}\text { Describe method of data extraction from reports (e.g., piloted forms, } \\
\text { independently, in duplicate) and any processes for obtaining and confirming } \\
\text { data from investigators. }\end{array}$ & 2,3 \\
\hline Data items & 11 & $\begin{array}{l}\text { List and define all variables for which data were sought (e.g., PICOS, } \\
\text { funding sources) and any assumptions and simplifications made. }\end{array}$ & 2,3 \\
\hline $\begin{array}{l}\text { Risk of bias in } \\
\text { individual studies }\end{array}$ & 12 & $\begin{array}{l}\text { Describe methods used for assessing risk of bias of individual studies } \\
\text { (including specification of whether this was done at the study or outcome } \\
\text { level), and how this information is to be used in any data synthesis. }\end{array}$ & $\mathrm{n} / \mathrm{a}$ \\
\hline Summary measures & 13 & State the principal summary measures (e.g., risk ratio, difference in means). & $\mathrm{n} / \mathrm{a}$ \\
\hline Synthesis of results & 14 & $\begin{array}{l}\text { Describe the methods of handling data and combining results of studies, if } \\
\text { done, including measures of consistency }\left(\text { e.g., } \mathrm{I}^{2}\right) \text { for each meta-analysis. }\end{array}$ & $14,15,16$ \\
\hline $\begin{array}{l}\text { Risk of bias across } \\
\text { studies }\end{array}$ & 15 & $\begin{array}{l}\text { Specify any assessment of risk of bias that may affect the cumulative } \\
\text { evidence (e.g., publication bias, selective reporting within studies). }\end{array}$ & $\mathrm{n} / \mathrm{a}$ \\
\hline Additional analyses & 16 & $\begin{array}{l}\text { Describe methods of additional analyses (e.g., sensitivity or subgroup } \\
\text { analyses, meta-regression), if done, indicating which were pre-specified. }\end{array}$ & $\mathrm{n} / \mathrm{a}$ \\
\hline \multicolumn{4}{|l|}{ RESULTS } \\
\hline Study selection & 17 & $\begin{array}{l}\text { Give numbers of studies screened, assessed for eligibility, and included in the } \\
\text { review, with reasons for exclusions at each stage, ideally with a flow diagram. }\end{array}$ & 3,12 \\
\hline $\begin{array}{l}\text { Study } \\
\text { characteristics }\end{array}$ & 18 & $\begin{array}{l}\text { For each study, present characteristics for which data were extracted (e.g., } \\
\text { study size, PICOS, follow-up period) and provide the citations. }\end{array}$ & $3,9,10$ \\
\hline $\begin{array}{l}\text { Risk of bias within } \\
\text { studies }\end{array}$ & 19 & $\begin{array}{l}\text { Present data on risk of bias of each study and, if available, any outcome level } \\
\text { assessment (see item 12). }\end{array}$ & $\mathrm{n} / \mathrm{a}$ \\
\hline $\begin{array}{l}\text { Results of } \\
\text { individual studies }\end{array}$ & 20 & $\begin{array}{l}\text { For all outcomes considered (benefits or harms), present, for each study: } \\
\text { (a) simple summary data for each intervention group (b) effect estimates and } \\
\text { confidence intervals, ideally with a forest plot. }\end{array}$ & 3,4 \\
\hline
\end{tabular}


Table 4. PRISMA checklist (Continued)

\begin{tabular}{|l|l|l|l|}
\hline Section/topic & $\#$ & Checklist item & $\begin{array}{l}\text { Reported } \\
\text { on page \# }\end{array}$ \\
\hline Synthesis of results & 21 & $\begin{array}{l}\text { Present results of each meta-analysis done, including confidence intervals } \\
\text { and measures of consistency. }\end{array}$ & 3 \\
\hline $\begin{array}{l}\text { Risk of bias across } \\
\text { studies }\end{array}$ & 22 & Present results of any assessment of risk of bias across studies (see Item 15). & n/a \\
\hline Additional analysis & 23 & $\begin{array}{l}\text { Give results of additional analyses, if done (e.g., sensitivity or subgroup } \\
\text { analyses, meta-regression [see Item 16]). }\end{array}$ & n/a \\
\hline DISCUSSION & 24 & $\begin{array}{l}\text { Summarize the main findings including the strength of evidence for each } \\
\text { main outcome; consider their relevance to key groups (e.g., healthcare } \\
\text { providers, users, and policy makers). }\end{array}$ & 3,4 \\
\hline $\begin{array}{l}\text { Summary of } \\
\text { evidence }\end{array}$ & 25 & $\begin{array}{l}\text { Discuss limitations at study and outcome level (e.g., risk of bias), and at } \\
\text { review-level (e.g., incomplete retrieval of identified research, reporting bias). }\end{array}$ & 4,5 \\
\hline $\begin{array}{l}\text { Limitations } \\
\text { Conclusions }\end{array}$ & 26 & $\begin{array}{l}\text { Provide a general interpretation of the results in the context of other } \\
\text { evidence, and implications for future research. }\end{array}$ & 5 \\
\hline \multicolumn{2}{|l}{} & $\begin{array}{l}\text { Describe sources of funding for the systematic review and other support } \\
\text { (e.g., supply of data); role of funders for the systematic review. }\end{array}$ & Title Page \\
\hline FUNDING & Funding &
\end{tabular}

From: Moher D, Liberati A, Tetzlaff J, Altman DG, The PRISMA Group (2009). Preferred Reporting Items for Systematic Reviews and Meta-Analyses: The PRISMA Statement. PLoS Med 6(7):e1000097. doi:10.1371/journal.pmed1000097 For more information, visit: www.prisma-statement.org.

Article citation: Dundar Y, Mandle Q, Samantray J, Hotaling J, Rizi SM, Cramer J, Lin H-S, Raza SN. Clinical value of pulmonary metastasectomy for thyroid malignancies: a systematic review and meta-analysis. The Southwest Respiratory and Critical Care Chronicles 2019;7(31):24-33

From: Department of Otolaryngology-Head and Neck Surgery (YD, QM, JH, SMR, JC, HSL, SNR), Wayne State University School of Medicine, Detroit, Ml; Barbara Ann Karmanos Cancer Institute (YD, JH, JC, HSL, SNR), Wayne State University School of Medicine, Detroit, MI; Department of Internal Medicine (JS), Wayne State University School of Medicine, Detroit, MI. Submitted: 9/22/2019

Accepted: 10/16/2019

Reviewers: Marcella Rivas MD, Duke Appiah PhD Conflicts of interest: none

This work is licensed under a Creative Commons Attribution-ShareAlike 4.0 International License.

\section{REFERENCES}

1. Haugen BR, Alexander EK, Bible KC, et al. American Thyroid Association management guidelines for adult patients with thyroid nodules and differentiated thyroid cancer: The American Thyroid Association Guidelines Task Force on thyroid nodules and differentiated thyroid cancer. Thyroid 2016;26:1-133.

2. Porterfield JR, Cassivi SD, Wigle DA, et al. Thoracic metastasectomy for thyroid malignancies. Euro J Cardio-thoracic Surg 2009;36(1):155-158.

3. Yang X, Liang J, Li TJ, et al. Postoperative stimulated thyroglobulin level and recurrence risk stratification in differentiated thyroid cancer. Chin Med J 2015;125.

4. Pak H, Gourgiotis L, Chang W, et al. Role of metastasectomy in the management of thyroid carcinoma: The NIH experience. J Surg Oncol 2003;82:10-18.

5. Chopra S, Garg A, Ballal S, et al. Lung metastases from differentiated thyroid carcinoma: prognostic factors related to remission and disease-free survival. Clin Endocrinol (Oxf) 2015;82:445-52. 
6. Cho SW, Choi HS, Yeom GJ, et al. Long-term prognosis of differentiated thyroid cancer with lung metastasis in Korea and its prognostic factors. Thyroid 2014;24:277-86.

7. Moneke I, Kaifi JT, Kloeser R, et al. Pulmonary metastasectomy for thyroid cancer as salvage therapy for radioactive iodine-refractory metastases. Euro J Card-Thor Surg 2018; 53(3):625-630.

8. Sabra MM, Dominguez JM, Grewal RK, et al. Clinical outcomes and molecular profile of differentiated thyroid cancers with radioiodine-avid distant metastases. J Clin Endocrinol Metab 2013;98:E829-36.

9. Durante C, Haddy N, Baudin E, et al. Long-term outcome of 444 patients with distant metastases from papillary and follicular thyroid carcinoma: benefits and limits of radioiodine therapy. J Clin Endocrinol Metab 2006;91:2892-9.

10. O'Neill CJ, Oucharek J, Learoyd D, et al. Standard and emerging therapies for metastatic differentiated thyroid cancer. Oncologist 2010;15:146-56.

11. Schlumberger M, Tahara M, Wirth LJ, et al. Lenvatinib versus placebo in radioiodine refractory thyroid cancer. N Engl J Med 2015;372:621-630.

12. Brose MS, Nutting CM, Jarzab B, et al. Sorafenib in radioactive iodine-refractory, locally advanced or metastatic differentiated thyroid cancer: a randomised, double-blind, phase 3 trial. Lancet 2014;384:319-328.

13. Leboulleux $\mathrm{S}$, Bastholt L, Krause $\mathrm{T}$, et al. Vandetanib in locally advanced or metastatic differentiated thyroid cancer: a randomised, double-blind, phase 2 trial. Lancet Oncol 2012;13:897-90.

14. Liu D, Labow DM, Dang N, et al. Pulmonary metastasectomy for head and neck cancer. Ann Surg Oncol 1999;6:572.
15. Finley RK, Verazin GT, Driscoll DL, et al. Results of surgical resection of pulmonary metastases of squamous cell carcinoma of the head and neck. Am J Surg 1992;164: 594-8.

16. Alexander J, Haight C. 1947. Pulmonary resection for solitary metastatic sarcomas and carcinomas, Surg Gynecol Obstet 1947;85:129-146.

17. Thomford NR, Woolner LB, Clagett OT. The surgical treatment of metastatic tumors in the lungs, J Thorac Cardiovasc Surg 1965;49:357-363.

18. Pastorino U, Buyse M, Friedel G, et al. Long-term results of lung metastasectomy: prognostic analyses based on 5206 cases. J Thorac Cardiovasc Surg 1997;113:37-49.

19. Dossett LA, Toloza EM, Fontaine J, et al. Outcomes and clinical predictors of improved survival in a patients undergoing pulmonary metastasectomy for sarcoma. J Surg Oncol 2015;112:103-6.

20. Mazzaferri EL, Jhiang SM. Long-term impact of initial surgical and medical therapy on papillary and follicular thyroid cancer. Am J Med 1994;97:418.

21. Khan JH, McElhinney DB, Rahman, et al. Pulmonary metastases of endocrine origin: the role of surgery. Chest 1998; 114:526-534.

22. Protopapas AD, Nicholson AG, Vini L, et al. Thoracic metastasectomy in thyroid malignancies. Ann Thor Surg 2001;72(6): 1906-1908.

23. Sampson E, Brierley JD, Le LW, et al. Clinical management and outcome of papillary and follicular (differentiated) thyroid cancer presenting with distant metastasis at diagnosis. Cancer 2007;110(7):1451-1456. 